Article

\title{
Grain Size Effect on the Mechanical Behavior of Metastable Fe-23Cr-8.5Ni Alloy
}

\author{
Lin Xie ${ }^{1,2, *}$, Chunpeng Wang ${ }^{1}$, Yuhui Wang ${ }^{3,4}$, Guilin $\mathrm{Wu}^{2}$ (D) and Xiaoxu Huang ${ }^{2,5, *}$ \\ 1 School of Engineering and Technology, Zunyi Normal University, Zunyi 563006, China \\ 2 International Joint Laboratory for Light Alloys (MOE), College of Material Science and Engineering, \\ Chongqing University, Chongqing 400044, China \\ 3 State Key Laboratory of Metastable Materials Science and Technology, Yanshan University, \\ Qinhuangdao 066004, China \\ 4 National Engineering Research Center for Equipment and Technology of Cold Strip Rolling, \\ Yanshan University, Qinhuangdao 066004, China \\ 5 Department of Mechanical Engineering, Technical University of Denmark, DK-2800 Kgs. Lyngby, Denmark \\ * Correspondence: linxie@cqu.edu.cn (L.X.); xiaoxuhuang@cqu.edu.cn (X.H.)
}

Received: 3 June 2019; Accepted: 25 June 2019; Published: 29 June 2019

check for updates

\begin{abstract}
An Fe-23Cr-8.5Ni alloy was used as a model material to study the grain size effect on the mechanical behavior of metastable duplex metal. Alloy samples with different grain sizes ranging from 0.1 to $2 \mu \mathrm{m}$ were prepared by cold-rolling and annealing. A structural refinement to about $0.1 \mu \mathrm{m}$ results in a high yield strength but very limited ductility. A significant improvement of ductility occurred at the grain size of about $0.4 \mu \mathrm{m}$. A further increase in grain size results in a decreased strength and a slightly improved ductility. The alloy with a grain size of about $0.4 \mu \mathrm{m}$ exhibits an excellent combination of strength and ductility, where the yield strength and tensile elongation are increased up to $738 \mathrm{MPa}$ and $29 \%$ as compared to $320 \mathrm{MPa}$ and $33 \%$ of a coarse-grained (about $2 \mu \mathrm{m}$ ) sample, respectively. The origin of the excellent mechanical properties was attributed to the unique deformation characteristics associated with the transformation induced plasticity and the development of back stress.
\end{abstract}

Keywords: mechanical properties; metastable; back stress; grain size

\section{Introduction}

It is well known that grain size plays an important role in determining the mechanical properties of metals. Nonetheless, high strength and ductility are often mutually exclusive when the grain size refines down to sub-micrometer or nanometer scales [1], and hence, managing both is full of challenges. This dilemma between strength and ductility in ultrafine-grained (UFG) metals has been sought through structural architectures such as bimodal (or multi-modal) grain size distribution [2,3], transformation and twinning induced plasticity (TRIP and TWIP) [4,5], and a mixture of dissimilar phases with different properties [6].

Among these structural design strategies, dual phase structures have attracted high interest for their potential to manage both strength and ductility, which has usually been applied in steels [7]. The differences in mechanical properties between constituent phases lead to an inhomogeneous stress and strain partitioning between them, resulting in a heterogeneous distribution of plastic strains across phase interfaces [8]. This interaction between two phases requires the generation of geometrically necessary dislocations (GNDs) at phase interfaces to accommodate the plastic strain gradient [9], which has a potential to improve the dislocation storage, and hence, contributes to the strain hardening.

Duplex steels containing ferrite $(\alpha)$ and austenite $(\gamma)$ are an important class of dual-phase alloys. Their importance is manifested in the good combination of strength and ductility. More importantly, 
these kinds of duplex alloys can become metastable by adjusting the chemical compositions, in which the austenite could transform into $\alpha^{\prime}$-martensite during deformation [10-12]. The deformation induced martensitic transformation (DIMT) is usually accompanied by a TRIP effect, leading to enhanced strain hardening and improved ductility as a result $[13,14]$. So the duplex structure combined with the TRIP effect is a promising strategy to overcome the strength-ductility trade-off in UFG metals. However, grain size also plays an important role in determining the TRIP effect. Investigations on metastable austenitic steels [15-17] show that grain refinement retards the DIMT and hence suppresses the TRIP effect. However, the grain size effect on the mechanical behavior of metastable duplex alloys, especially when the grain size refines down to sub-micrometer scales, has not been investigated in sufficient detail.

In the present study, a Fe-23Cr-8.5Ni alloy was used as a model material of metastable duplex alloy. The grain-size scales of this alloy were tailored by cold-rolling and annealing, and samples with grain sizes of about $0.1,0.4,1$, and $2 \mu \mathrm{m}$ were obtained to investigate the grain size effect on the mechanical behavior.

\section{Materials and Methods}

A Fe-23Cr-8.5Ni alloy has been chosen as a model material for its representative structure that ensures nearly equal volume fractions of ferrite and metastable austenite. The chemical composition of the alloy investigated are $0.001 \% \mathrm{C},<0.01 \% \mathrm{Si},<0.01 \% \mathrm{Mn},<0.001 \% \mathrm{P},<0.001 \% \mathrm{~S}, 8.52 \% \mathrm{Ni}, 22.9 \% \mathrm{Cr}$, $0.002 \% \mathrm{~N}, 0.04 \% \mathrm{O}$, and the balance $\mathrm{Fe}$ (mass $\%$ ). The alloy was prepared by vacuum induction melting and was homogenized at $1150{ }^{\circ} \mathrm{C}$ for $2 \mathrm{~h}$ and then hot forged at temperatures above $900{ }^{\circ} \mathrm{C}$ to produce a plate that is suitable for cold-rolling. Afterwards, the hot forged plate was cold-rolled to a thickness reduction of $90 \%$ and then annealed at 700,900 , and $1000{ }^{\circ} \mathrm{C}$ for $30 \mathrm{~min}$, in order to tailor the structure with grain-size scales of about $0.1,0.4,1$, and $2 \mu \mathrm{m}$, respectively.

The austenite phase in the present alloy is mechanically unstable, which is prone to transform into martensite when subjected to deformation. The volume fraction of austenite was measured by X-ray diffraction (XRD) under a Rigaku D/max 2500 diffractometer with $\mathrm{Cu} K \alpha$ radiation and a step size of $0.02^{\circ}$. A quantitative measurement based on XRD data was used to estimate the volume fraction of austenite, with the following equation [18]:

$$
f_{\gamma}=\frac{\frac{1}{n} \sum_{i=1}^{n} \frac{I_{\gamma}^{i}}{R_{\gamma}^{i}}}{\frac{1}{n} \sum_{i=1}^{n} \frac{I_{\alpha}^{i}}{R_{\alpha}^{i}}+\frac{1}{n} \sum_{i=1}^{n} \frac{I_{\gamma}^{i}}{R_{\gamma}^{i}}}
$$

where $R_{\alpha}$ and $R_{\gamma}$ are the theoretical intensity for the (hkl) plane of ferrite and austenite, respectively; $I_{\alpha}$ and $I_{\gamma}$ refer to the integrated intensity for the (hkl) plane of ferrite and austenite, respectively; and $n$ indicates the number of (hkl) peaks for ferrite or austenite.

Microstructures of alloy samples were characterized by transmission electron microscopy (TEM) using a JEM-2100 electron microscope (JEOL, Boston, MA, USA) operated at $200 \mathrm{kV}$. Specimens for TEM observation were first mechanically polished to a thickness of $70 \mu \mathrm{m}$, and then electropolished under a Tenupol-5 double-jet polisher in an electrolyte of $25 \%$ perchloric acid and $75 \%$ ethanol (vol. $\%$ ) with a voltage of $20 \mathrm{~V}$ at $-20^{\circ} \mathrm{C}$. The observed plane was the longitudinal section containing the rolling direction (RD) and normal direction (ND).

Mechanical behaviors of alloy samples were revealed by uniaxial tensile tests including monotonic tensile loading and tensile loading-unloading-reloading (LUR) tests, which were conducted with an MTS793 testing machine (MTS, Eden Prairie, MN, USA) operating at a quasi-static rate of $6 \times 10^{-4} \mathrm{~s}^{-1}$ at room temperature. Dog-bone-shaped plates with $25 \mathrm{~mm}$ in gauge length and $5 \mathrm{~mm}$ in gauge width were machined from the alloy samples along the RD. An extensometer was attached on the plate to measure tensile strain. For the LUR test, five LUR cycles were performed. The specimen was unloaded at a certain strain by a stress-control mode to $20 \mathrm{~N}$ at an unloading rate of $200 \mathrm{~N} \mathrm{~min}^{-1}$ and then 
reloaded to the same applied stress before the next cycle. Both XRD and tensile tests were repeated three times for each condition.

\section{Results and Discussion}

The present alloy containing metastable austenite experienced a DIMT and its reversion transformation during cold-rolling and annealing. As shown in Figure 1, the XRD spectrum of the cold-rolled (CR) sheet is characterized by only the diffraction peaks of ferrite (also including the $\alpha^{\prime}$-martensite), indicating the completion of DIMT. After annealing above $700{ }^{\circ} \mathrm{C}$ for $30 \mathrm{~min}$, the deformation induced martensite transformed back to austenite, resulting in a reappearance of austenite diffraction peaks. The volume fraction of austenite was measured to be $51.1 \%$ for the $700{ }^{\circ} \mathrm{C}$ annealed sample, $57.2 \%$ for the $900{ }^{\circ} \mathrm{C}$ annealed, and $56.1 \%$ for the $1000{ }^{\circ} \mathrm{C}$ annealed sample.
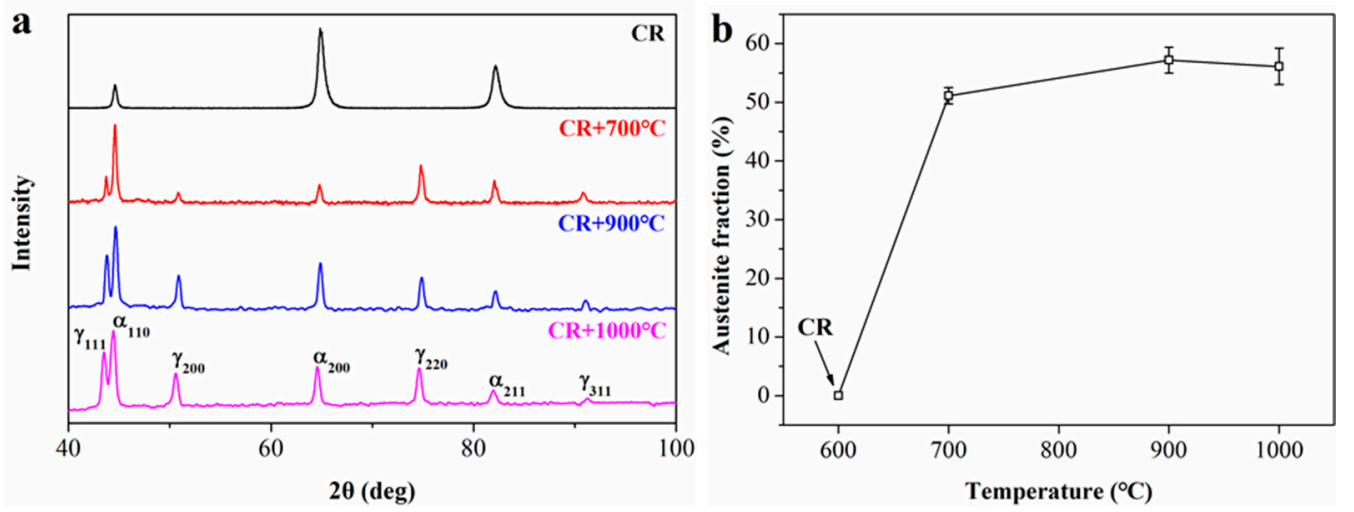

Figure 1. (a) Representative XRD spectrums and (b) the quantified austenite volume fractions of samples cold-rolled and annealed.

Figure 2a is a representative TEM image of the cold-rolled sheet, where the microstructure is characterized by a laminated structure with extended boundaries parallel to the RD. Since the ferrite and $\alpha^{\prime}$-martensite have an almost identical crystal structure, they are difficult to be separated based on crystallographic analysis and are also morphologically indistinguishable. The distribution of measured boundary spacing is plotted in Figure 2b, showing an average value of $72 \mathrm{~nm}$.
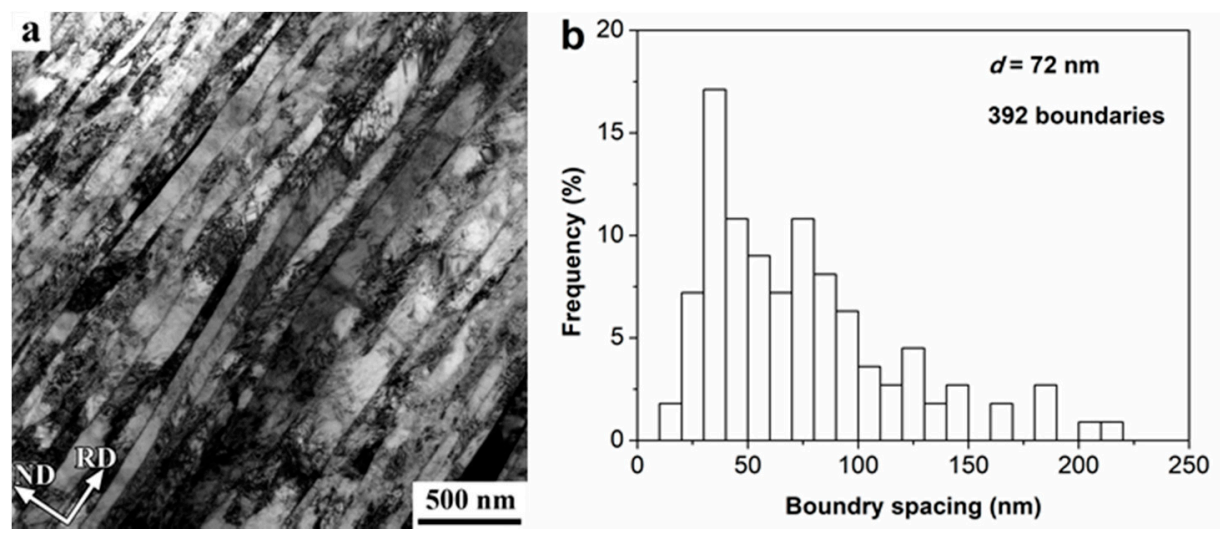

Figure 2. Microstructural characterization of the cold-rolled sample: (a) Representative TEM image; (b) The distribution of lamellar boundary spacing.

After annealing at $700{ }^{\circ} \mathrm{C}$ for $30 \mathrm{~min}$, the deformed lamellar structure was evolved into a recrystallized duplex structure consisting of austenite and ferrite. A representative TEM image and its boundary sketch are shown in Figure 3a,b, respectively, in which the austenite and ferrite were identified by electron diffraction. Obvious structural coarsening can be seen in this annealed sample. 
The grain size distribution shown in Figure $3 \mathrm{c}$ results in an average grain size of $401 \mathrm{~nm}$ for austenite and $347 \mathrm{~nm}$ for ferrite. After annealing at $900{ }^{\circ} \mathrm{C}$ (see Figure 3d,e), the main evolution is structural coarsening without a significant change in the structural morphology. Statistical results of grain sizes (Figure 3f) show an average value of about $1.1 \mu \mathrm{m}$ for both austenite and ferrite. Annealing at $1000{ }^{\circ} \mathrm{C}$ led to a further structural coarsening (Figure 3h,i), resulting in an average grain size of $2.3 \mu \mathrm{m}$ for austenite and $1.8 \mu \mathrm{m}$ for ferrite (Figure $3 \mathrm{i}$ ). The structural parameters for the above four samples are summarized in Table 1. It is seen that the alloy samples with grain size scales of about $0.1,0.4,1$, and $2 \mu \mathrm{m}$ are obtained.
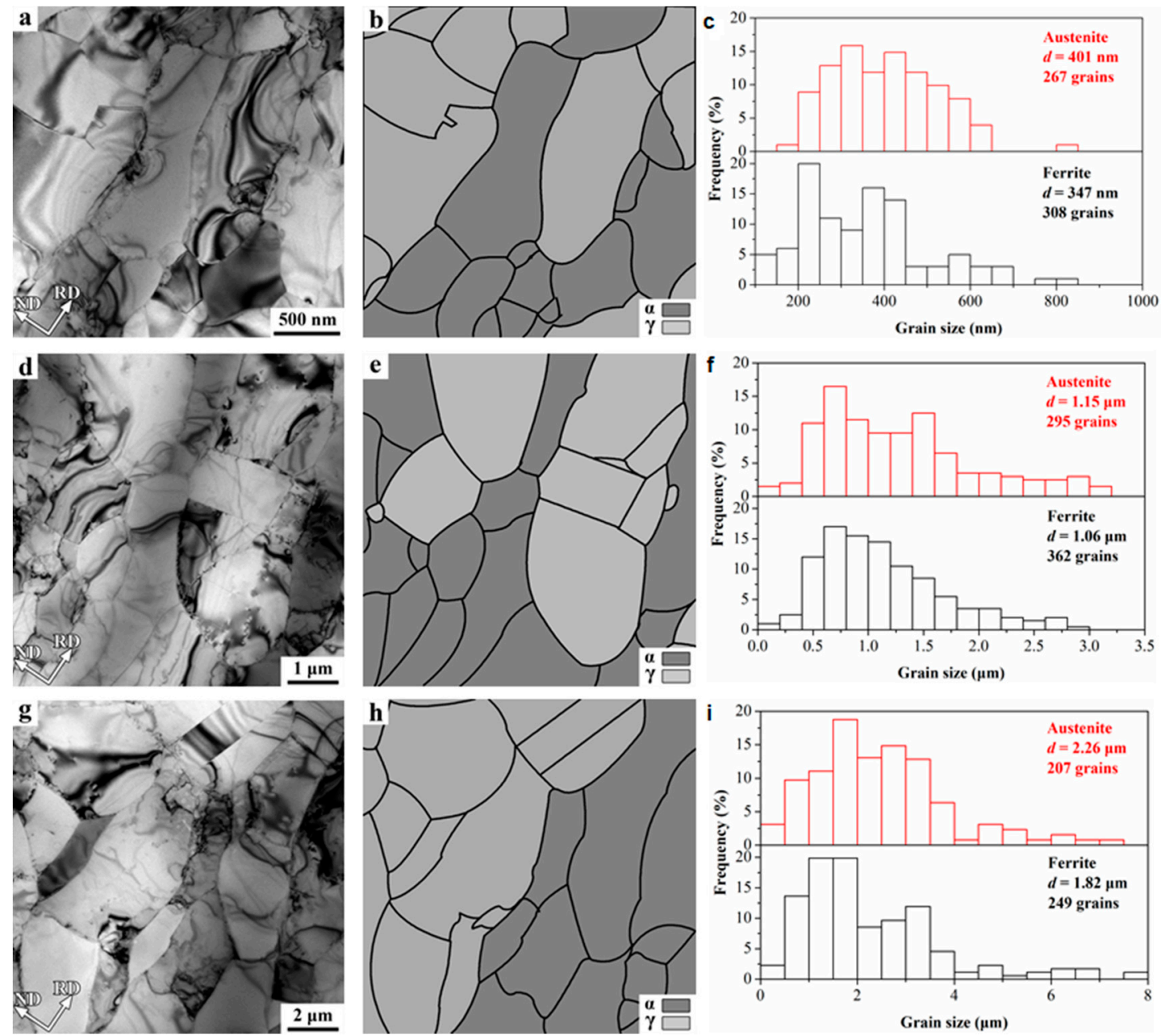

Figure 3. Microstructural characterizations of annealed samples: $(\mathbf{a}-\mathbf{c})$ Representative TEM image, the corresponding boundary sketch, and the grain size distribution of the sample annealed at $700{ }^{\circ} \mathrm{C}$ for 30 min, respectively; (d-f) Representative TEM image, the corresponding boundary sketch, and the grain size distribution of the sample annealed at $900^{\circ} \mathrm{C}$ for $30 \mathrm{~min}$, respectively; (g-i) Representative TEM image, the corresponding boundary sketch, and the grain size distribution of the sample annealed at $1000{ }^{\circ} \mathrm{C}$ for $30 \mathrm{~min}$, respectively.

Figure 4 shows the engineering stress-strain curves of the cold-rolled and annealed samples for grain sizes up to micrometer scale. The cold-rolled sample due to its UFG deformation structure (see curve 1) shows a high yield strength of $1298 \pm 14 \mathrm{MPa}$. Nonetheless, the plastic instability manifested as tensile necking occurs at a strain of less than $2 \%$, exhibiting a mechanical behavior typical of heavily deformed metals. The $700{ }^{\circ} \mathrm{C}$ annealed sample with a grain-size scale of about $0.4 \mu \mathrm{m}$ (curve 2) exhibits a discontinuous yielding with $3 \%$ Lüders elongation and a yield plateau stress of $738 \pm 6 \mathrm{MPa}$, followed by a wide strain hardening range that results in a total elongation of $29 \pm 0.9 \%$. The $900{ }^{\circ} \mathrm{C}$ annealed 
sample with a grain size of about $1 \mu \mathrm{m}$ (curve 3 ) shows a continuous yielding and a wider strain hardening stage. The yield strength and total elongation are $437 \pm 8 \mathrm{MPa}$ and $35 \pm 1.2 \%$, respectively. A further increase of grain size to about $2 \mu \mathrm{m}\left(100{ }^{\circ} \mathrm{C}\right.$ annealed, curve 4$)$ leads to a decreased yield strength of $320 \pm 7 \mathrm{MPa}$, without apparent change of yielding behavior and ductility. These results reveal a transition of the flow behavior from continuous to discontinuous when the grain size is below about $1 \mu \mathrm{m}$, which leads to a significant increase in the yield strength in the $700{ }^{\circ} \mathrm{C}$ annealed sample. Note that the yield strength of the $700{ }^{\circ} \mathrm{C}$ annealed sample is more than twice of that of the $1000{ }^{\circ} \mathrm{C}$ annealed sample, while the total tensile elongations are comparable.

Table 1. Structural parameters of samples cold-rolled and annealed.

\begin{tabular}{llccc}
\hline \multicolumn{1}{c}{ Sample } & Structural Feature & $\begin{array}{c}\text { Grain Size } \\
(\alpha)\end{array}$ & $\begin{array}{c}\text { Grain Size } \\
(\gamma)\end{array}$ & $\begin{array}{c}\text { Volume Fraction } \\
(\gamma)\end{array}$ \\
\hline $\mathrm{CR}$ & $\begin{array}{l}\text { UFG lamellar structure } \\
\left(\alpha+\alpha^{\prime}\right)\end{array}$ & $72 \pm 24 \mathrm{~nm}$ & - & $0 \%$ \\
$\mathrm{CR}+700^{\circ} \mathrm{C}$ & $\begin{array}{l}\text { UFG recrystallized structure } \\
(\alpha+\gamma)\end{array}$ & $347 \pm 137 \mathrm{~nm}$ & $401 \pm 122 \mathrm{~nm}$ & $51.1 \pm 1.4 \%$ \\
$\mathrm{CR}+900^{\circ} \mathrm{C}$ & $\begin{array}{l}\mathrm{CG} \text { recrystallized structure } \\
(\alpha+\gamma)\end{array}$ & $1.06 \pm 0.37 \mu \mathrm{m}$ & $1.15 \pm 0.43 \mu \mathrm{m}$ & $57.2 \pm 2.2 \%$ \\
$\mathrm{CR}+1000^{\circ} \mathrm{C}$ & $\begin{array}{l}\mathrm{CG} \text { recrystallized structure } \\
(\alpha+\gamma)\end{array}$ & $1.82 \pm 0.55 \mu \mathrm{m}$ & $2.26 \pm 0.69 \mu \mathrm{m}$ & $56.1 \pm 3.1 \%$ \\
\hline
\end{tabular}

${ }^{*}$ CG refers to coarse-grained.

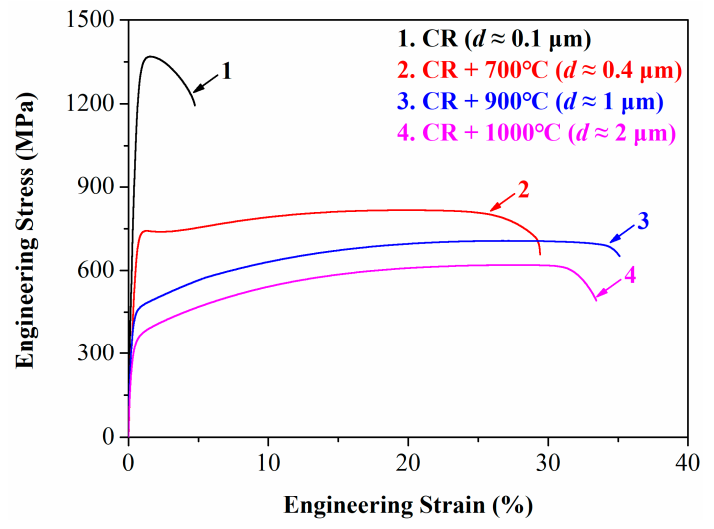

Figure 4. Engineering stress-strain curves of samples with different grain size scales.

In order to verify the occurrence of DIMT during tensile deformation and the corresponding TRIP effect on the tensile behavior, XRD tests were conducted to quantify the volume fractions of austenite for the annealed samples after tensile testing. Several representative XRD spectrums taken from the fractured areas are shown in Figure $5 \mathrm{a}$. The difference in the volume fraction of austenite before and after tensile testing, $\Delta f_{\gamma}$, was quantified and is shown in Figure $5 \mathrm{~b}$. It was observed that all the annealed samples exhibit a substantial reduction in austenite volume fraction $\left(\Delta f_{\gamma}\right)$ after tensile testing to failure, indicating the occurrence of DIMT during the tensile testing. The results also show a clear dependence of $\Delta f_{\gamma}$ on the grain size scale. As the austenite grain size increases from 0.4 to $1.1 \mu \mathrm{m}$, the $\Delta f_{\gamma}$ significantly increases from $14.7 \%$ to $28.4 \%$. However, negligible change of $\Delta f_{\gamma}$ can be observed as the austenite grain size increases from 1.1 to $2.3 \mu \mathrm{m}$. The occurrence of DIMT is expected to contribute to the enhancement in the strain hardening and the tensile ductility. However, the large difference in the extent of DIMT observed between the sample of $0.4 \mu \mathrm{m}$ grain size and the two samples with $1-2 \mu \mathrm{m}$ grain sizes cannot be fully explained by the difference in the TRIP effect. 

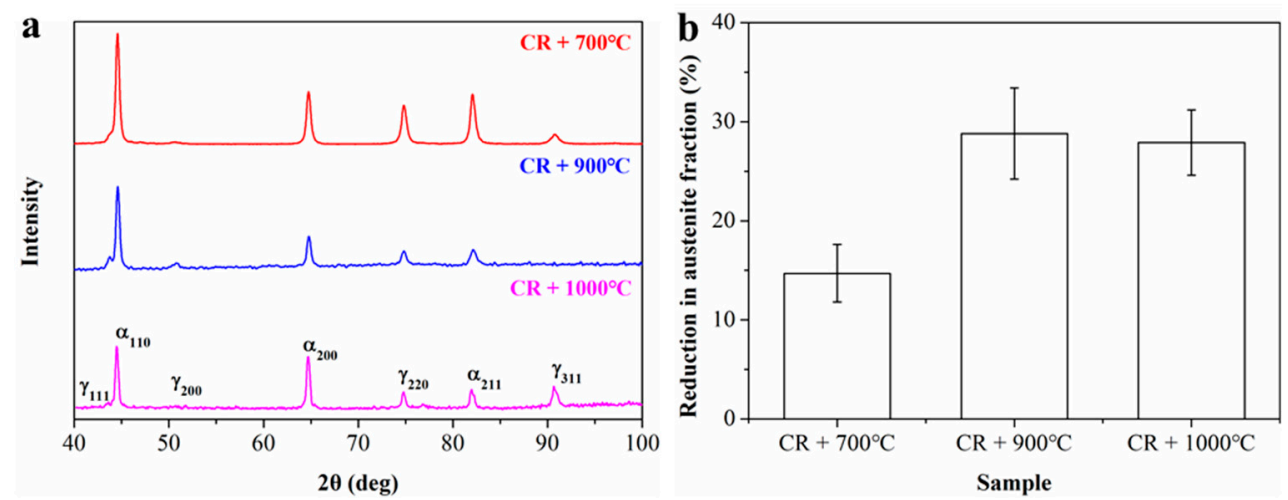

Figure 5. (a) Representative XRD spectrums and (b) the corresponding quantified results of annealed samples after tensile testing to failure.

Besides the TRIP effect, the good combination of strength and ductility observed in the present alloy may also have its cause in the composite nature of plastic deformation. Since the present alloy is a dual phase material consisting of austenite and ferrite, there is a structural heterogeneity due to the differences in mechanical properties between the two phases [19]. At the onset of deformation, austenite due to its lower hardness [20] plastically deforms first, initiating the multiplication of dislocation. Nonetheless, the austenite is constrained by surrounding harder ferrite so that dislocations in austenite grains are accumulated and blocked at phase interfaces. Such dislocation configurations produce localized internal stresses which finally develop into long-range back stress [21] to make it difficult for dislocations to transfer from austenite to ferrite until the latter plastically deforms at a larger macroscopic strain. As a result, the back stress and its evolution with strain have a significant contribution to the global flow stress and strain hardening, as previously proved in heterogeneous-structured metals [22].

The back stress arising from structural heterogeneity is expected to be further enhanced when the deformation is associated with martensitic transformation [23], which led to the investigation of the Bauschinger effect [24], from which the back stress could be estimated. Figure 6a shows the true stress-strain curve for the sample with a grain size scale of about $0.4 \mu \mathrm{m}$ after tensile LUR test. A representative hysteresis loop during the first unloading-reloading cycle could be observed in the inset of this figure, indicating a strong Bauschinger effect. The back stress is determined based on the tensile unloading-reloading hysteresis loop, which is described in detail elsewhere [25]. Figure 6b shows the evolution of back stress with strain. For comparison, the global true stress-strain curve and its strain hardening curve are also included. It is seen that the back stress $\left(\sigma_{\text {back }}\right)$ exhibits an increasing tendency similar to the global flow stress $\left(\sigma_{\text {global }}\right)$, which is determined to be $298 \mathrm{MPa}$ at the tensile strain of 0.02 and it increases up to $403 \mathrm{MPa}$ at the tensile strain of about 0.1. However, the strain hardening behaviors between the back stress $\left(\Theta_{\text {back }}\right)$ and global flow stress $\left(\Theta_{\text {global }}\right)$ are different. The $\Theta_{\text {back }}$ shows a monotonic decrease with strain, while for the $\Theta_{\text {global }}$, it exhibits a rapid drop during the Lüders deformation stage and subsequently a fast increase up to a true strain of 0.06 , followed by a slow decrease during further deformation. It is noteworthy that at the early stage (0.02-0.04), $\Theta_{\text {back }}$ shows much higher values than $\Theta_{\text {global }}$. This suggests that the back stress evolving with strain provides an extra strain hardening to the upturn of $\Theta_{\text {global }}[25,26]$, and therefore, plays an important role in the ductility. 

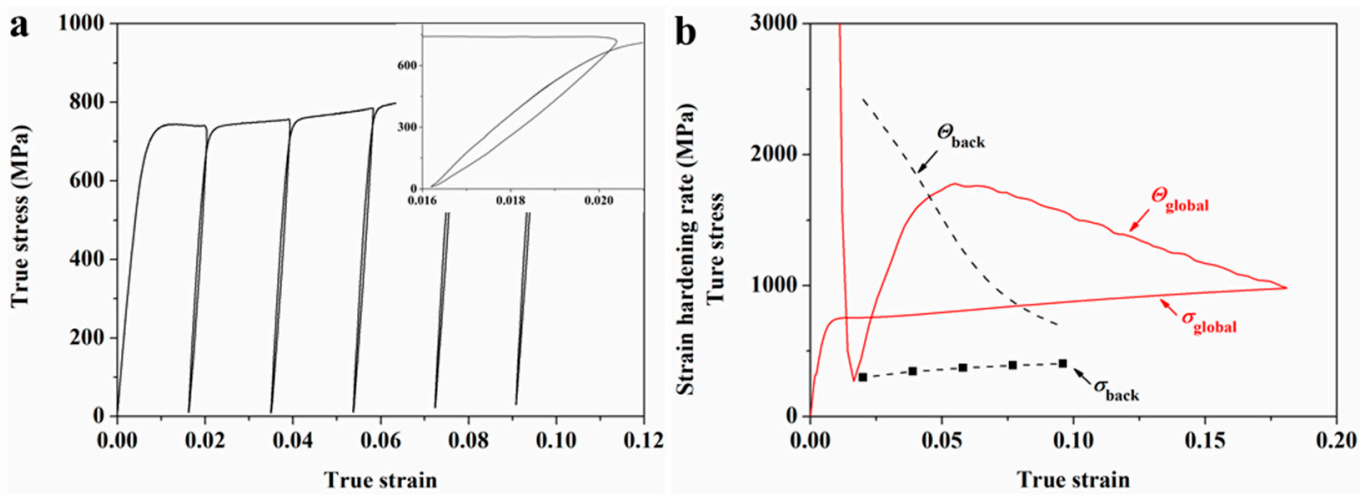

Figure 6. (a) The tensile loading-unloading-reloading (LUR) true stress-strain curve of the $700{ }^{\circ} \mathrm{C}$ annealed sample; (b) Back stress and its strain hardening.

Figure 7 shows the TEM images of the sample with a grain size scale of about $0.4 \mu \mathrm{m}$ after the tensile strain of 0.01 , where the structural heterogeneity is taken into account. Hereinto, Figure 7 a characterizes the representative deformed structure at the interface between austenite and ferrite. It could be seen that due to the difference in plastic response between the two phases [27], dislocations are mainly piled up and blocked on the austenite side. On the contrary, there are much fewer dislocations statistically stored on the ferrite side. In the austenite phase, on the other hand, a representative deformed structure shown in Figure $7 \mathrm{~b}$ confirms the occurrence of DIMT. The crystallographic relationship between the $\alpha^{\prime}$-martensite and its neighboring austenite obey the Kurdjumov-Sachs orientation relationship [28]. It is also seen that DIMT leads to a dislocation concentration in the neighboring austenite grain. The TEM observation clearly reveals the inhomogeneous dislocation configuration caused by the strain incompatibility of different phases. Large amounts of GNDs are generated at phase interfaces to accommodate the strain incompatibility $[29,30]$, which raises the back stress.
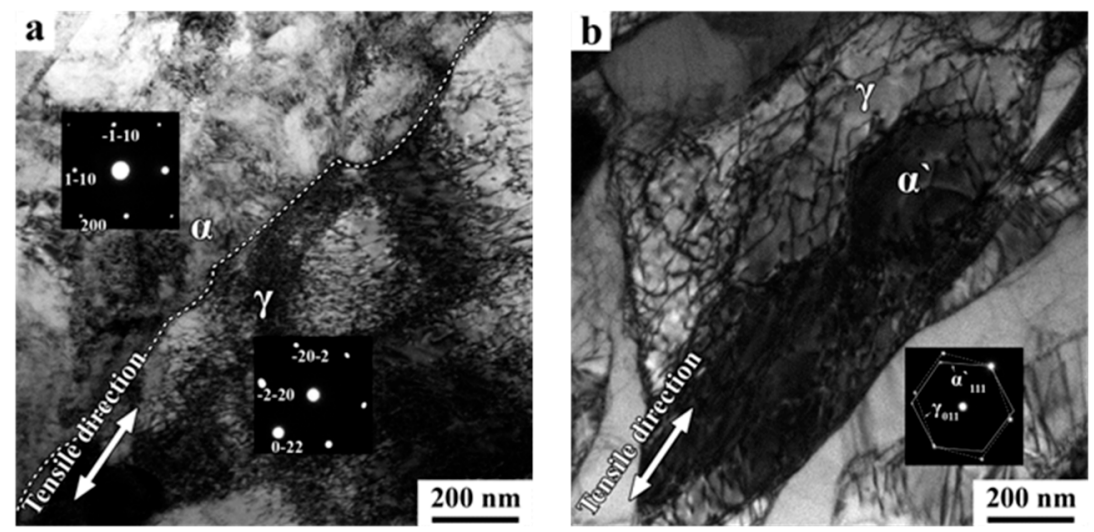

Figure 7. Representative TEM images revealing the deformed microstructures of the $700{ }^{\circ} \mathrm{C}$ annealed sample after tensile strain of 0.01: (a) At the phase interface between austenite and ferrite; (b) In the austenite phase where deformation induced martensitic transformation (DIMT) has occurred.

Like other conventional metals, the present alloy also shows a grain-size dependent mechanical behavior. Heavy cold-rolling leads to complete DIMT and significant structural refinement, resulting in a laminated structure composed of ferrite and $\alpha^{\prime}$-martensite. The laminated structure with an average boundary spacing of $72 \mathrm{~nm}$ gives the alloy a high yield strength that is four times higher than its CG $(2 \mu \mathrm{m})$ counterpart. However, the extremely small grains are incapable of storing dislocations to increase their density to the same extent as normally in coarse grains, leading to a severely reduced dislocation-mediated plasticity [31]. Therefore, the tensile elongation of the cold-rolled alloy is limited below $5 \%$, as usually reported for the vast majority of nanostructured metals produced by plastic deformation to high stains [32]. Annealing of the cold-rolled alloy at $700{ }^{\circ} \mathrm{C}$ for $30 \mathrm{~min}$ leads to a 
structural coarsening accompanied by a complete austenite reversion, resulting in a grain-size scale of about $0.4 \mu \mathrm{m}$, which is the finest grain size for the present alloy that allows approximately equal volume fractions of austenite and ferrite. The increase of grain size from 0.1 to $0.4 \mu \mathrm{m}$ significantly lowers the yield strength from 1.3 GPa to $738 \mathrm{MPa}$. However, there is an abrupt increase of ductility at this grain-size scale, which is much finer than the scale where a similar transition is reported for a number of single phase metals [33-37], which is usually above $1 \mu \mathrm{m}$. The unique deformation characteristics of the duplex structure and TRIP effect are responsible for the observed high ductility. As the grain size further increases by annealing at higher temperatures, the yield strength is further decreased while further improvement in tensile elongation is limited. Note that in the micrometer-grained scale, a grain refinement from 2 to $1 \mu \mathrm{m}$ leads to a slight increase of ductility. Similar results were also reported for both ferritic-martensitic and ferritic-austenitic dual phase alloys $[9,38,39]$. The increased densities of grain boundaries and phase interfaces due to structural refinement can increase the number of dislocation sources, giving rise to rapid dislocation multiplication and enhanced strain hardening [38], which is responsible for the observed improved ductility.

Based on the tensile results, the yield strength is plotted in Figure 8 against the inverse square root of grain size, exhibiting a clear Hall-Petch relationship. The fitted line shows a slope of $315.2 \mathrm{MPa} \mu \mathrm{m}^{2}$ and flow stress of $145 \mathrm{MPa}$ at an infinite grain size. This slope is comparable to that $\left(334.7 \mathrm{MPa} \mu \mathrm{m}^{2}\right)$ reported for a Fe-24Cr-4Ni-0.4Mo-0.1N duplex alloy [9]. However, the Fe-24Cr-4Ni-0.4Mo-0.1N alloy shows much higher flow stress ( $308 \mathrm{MPa}$ ) at an infinite grain size than the present alloy, which can be attributed to the differences in chemical compositions, especially to the solution strengthening effect imposed by nitrogen. The present study combined with previous research $[9,40]$ on Fe-Cr-Ni based duplex alloys, clearly reveal an extension of the Hall-Petch relationship from the micrometer scale to the sub-micrometer scale.

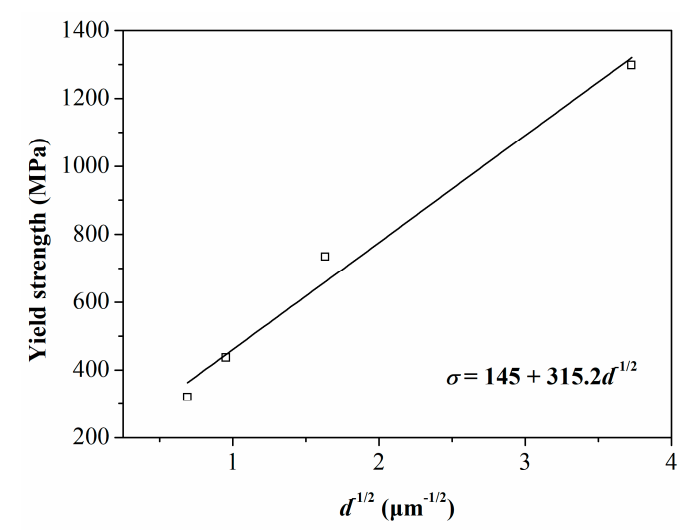

Figure 8. Yield strength vs. the inverse square root of grain size.

Many studies on metastable austenitic steels [15-17] indicate that the mechanical stability of austenite is increased with decreasing grain size. For the metastable duplex alloy, a previous investigation on medium-Mn duplex steel [41] also suggests that the DIMT can be significantly inhibited as the austenite grain size refines from $3 \mu \mathrm{m}$ down to $1 \mu \mathrm{m}$. In the case of the present alloy, the quantification results of DIMT during tensile deformation are similar for the austenite grain size ranged from 1.1-2.3 $\mu \mathrm{m}$. However, suppressed DIMT is observed when the austenite grain size refines down to $0.4 \mu \mathrm{m}$. Similar to the situation of deformation twinning, there is also critical stress that is required to activate DIMT [15]. The decrease in austenite grain size increases the strain energies required for both lattice displacement and shear deformation, resulting in reduced nucleation sites for the formation of martensite [42,43].

It is also noted that the alloy sample with a grain size of about $0.4 \mu \mathrm{m}$ shows a discontinuous yielding characterized by a yield point phenomenon and a Lüders elongation, instead of the continuous yielding in the CG samples. This has been usually observed in single phase metals such as Al [33], IF steel [37], and austenitic steel [44]. The discontinuous yielding behavior corresponds to a steep drop 
followed by a rapid upturn of strain hardening rate, which can be attributed to the lack of initial mobile dislocations and sudden multiplication of mobile dislocations [45]. Since there is a critical density of mobile dislocation required to initiate plastic deformation, which is increased with decreasing grain size [46]. As the grain size refines down to sub-micrometer scale, the initial density of mobile dislocation is insufficient and the yield point phenomenon occurs as a result.

Among the grain size scales investigated, the alloy with a grain size of about $0.4 \mu \mathrm{m}$ exhibits the best combination of strength and ductility. The yield strength in this grain size scale is 2.3 times higher than that in the grain size scale of about $2 \mu \mathrm{m}$, while the tensile elongation of the former is just slightly smaller than that of the latter. It is obvious that the metastable duplex structure has a good potential to manage both strength and ductility in the UFG scale. Although DIMT in this grain size scale is inhibited as compared to those in the CG scales, the volume fraction of austenite transformed into $\alpha^{\prime}$-martensite is still as high as $14.7 \%$, which is comparable to those of the retained austenite in TRIP-aided steels [47-49] and is, therefore, sufficient to trigger a TRIP effect. Moreover, DIMT introduces a new phase into the duplex structure, which increases the structural heterogeneity. The difference in mechanical properties between constituted phases and the existence of a large number of phase interfaces make it effective to develop back stress. On the one hand, the back stress gives rise to strengthening mechanisms enhancing the global strength above the strength that resulted from the rule of mixture [50]. On the other hand, the back stress increases with increasing strain, which provides extra strain hardening and contributes to the ductility.

\section{Conclusions}

Fe-23Cr-8.5Ni alloy samples with different grain-size scales ranging from about 0.1 to $2 \mu \mathrm{m}$ have been prepared by cold-rolling and annealing. The effect of grain size on mechanical behavior has been systematically studied. The main results are summarized as follows:

(1) Heavy cold-rolling leads to complete DIMT and significant structural refinement, resulting in a laminated structure with an average lamellar spacing of $72 \mathrm{~nm}$, which gives the alloy a high yield strength of $1.3 \mathrm{GPa}$ but a limited tensile elongation below $5 \%$.

(2) Annealing of the cold-rolled alloy at $700-1000{ }^{\circ} \mathrm{C}$ for $30 \mathrm{~min}$ leads to structural coarsening accompanied by a complete austenite reversion, resulting in decreased yield strength and improved ductility.

(3) Quantification of DIMT during tensile tests shows that the increase of austenite grain size from $401 \mathrm{~nm}$ to $1.1 \mu \mathrm{m}$ leads to an increase of the volume fraction of DIMT from $14.7 \%$ to $28.4 \%$. A further increase of austenite grain size from 1.1 to $2.3 \mu \mathrm{m}$ results in negligible change in the DIMT quantification.

(4) An excellent combination of strength and ductility was observed in the sample with an average grain size of $401 \mathrm{~nm}$ for austenite and $347 \mathrm{~nm}$ for ferrite. The yield strength and tensile elongation are increased up to $738 \mathrm{MPa}$ and $29 \%$ as compared to $320 \mathrm{MPa}$ and $33 \%$ of its CG (2.3 $\mu \mathrm{m}$ for austenite and $1.8 \mu \mathrm{m}$ for ferrite) counterpart, respectively.

(5) The excellent strength-ductility balance at the UFG scale can be attributed to the TRIP effect and the development of back stress resulting from the strain incompatibility between austenite, ferrite, and deformation induced martensite.

Author Contributions: Conceptualization-X.H.; Methodology-L.X. and G.W.; Validation-L.X., C.W. and Y.W.; Formal analysis-L.X., G.W. and X.H.; Data curation-L.X.; Writing-original draft preparation-L.X.; Writing, Review, and Editing-G.W. and X.H.; Supervision,-X.H.; Project administration-X.H.

Funding: This research was supported by the State Key Research and Development Program of MOST, China (2016YFB0700400), National Natural Science Foundation of China (NSFC, Nos.: 51421001 and 51871194), and Fundamental Research Funds for the Central Universities (No. 2018CDJDCL0019). The authors thank N. Tsuji for providing the material used in this study and for helpful discussions.

Conflicts of Interest: The authors declare no conflict of interest. 


\section{References}

1. Estrin, Y.; Vinogradov, A. Extreme grain refinement by severe plastic deformation: A wealth of challenging science. Acta Mater. 2013, 61, 782-817. [CrossRef]

2. Wang, Y.; Chen, M.; Zhou, F.; Ma, E. High tensile ductility in a nanostructured metal. Nature 2002, 419, 912-915. [CrossRef] [PubMed]

3. Niu, G.; Wu, H.; Zhang, D.; Gong, N.; Tang, D. Study on microstructure and properties of bimodal structured ultrafine-grained ferrite steel. Metals 2017, 7, 316. [CrossRef]

4. Wu, X.; Tao, N.; Hong, Y.; Lu, J.; Lu, K. $\gamma \rightarrow \varepsilon$ martensite transformation and twinning deformation in fcc cobalt during surface mechanical attrition treatment. Scr. Mater. 2005, 52, 547-551. [CrossRef]

5. Ma, Y.; Jin, J.E.; Lee, Y.K. A repetitive thermomechanical process to produce nano-crystalline in a metastable austenitic steel. Scr. Mater. 2005, 52, 1311-1315. [CrossRef]

6. Koch, C.C.; Scattergood, R.O.; Murty, K.L. The mechanical behavior of multiphase nanocrystalline materials. JOM 2007, 59, 66-70. [CrossRef]

7. Tasan, C.C.; Diehl, M.; Yan, D.; Bechtold, M.; Roters, F.; Schemmann, L.; Zheng, C.; Peranio, N.; Ponge, D.; Koyama, B.; et al. An overview of dual-phase steels: Advances in microstructure-oriented processing and micromechanically guided design. Annu. Rev. Mater. Res. 2015, 45, 391-431. [CrossRef]

8. Ankem, S.; Margolin, H.; Greene, C.A.; Neuberger, B.W.; Oberson, P.G. Mechanical properties of alloys consisting of two ductile phases. Prog. Mater. Sci. 2006, 51, 632-709. [CrossRef]

9. Chen, L.; Yuan, F.P.; Jiang, P.; Xie, J.J.; Wu, X.L. Simultaneous improvement of tensile strength and ductility in micro-duplex structure consisting of austenite and ferrite. Mater. Sci. Eng. A 2014, 618, 563-571. [CrossRef]

10. Choi, J.Y.; Ji, J.H.; Hwang, S.W.; Park, K.T. Strain induced martensitic transformation of Fe-20Cr-5Mn-0.2 Ni duplex stainless steel during cold rolling: effects of nitrogen addition. Mater. Sci. Eng. A 2011, 528, 6012-6019. [CrossRef]

11. Tavares, S.S.M.; Pardal, J.M.; Da Silva, M.R.; De Oliveira, C.A.S. Martensitic transformation induced by cold deformation of lean duplex stainless steel UNS S32304. Mater. Res. 2014, 17, 381-385. [CrossRef]

12. Breda, M.; Brunelli, K.; Grazzi, F.; Scherillo, A.; Calliari, I. Effects of cold rolling and strain-induced martensite formation in a SAF 2205 duplex stainless steel. Metall. Mater. Trans. A 2015, 46, 577-586. [CrossRef]

13. Jacques, P.; Furnémont, Q.; Mertens, A.; Delannay, F. On the sources of work hardening in multiphase steels assisted by transformation-induced plasticity. Philos. Mag. A 2001, 81, 1789-1812. [CrossRef]

14. Ryu, J.H.; Kim, D.I.; Kim, H.S.; Bhadeshia, H.K.D.H.; Suh, D.W. Strain partitioning and mechanical stability of retained austenite. Scr. Mater. 2010, 63, 297-299. [CrossRef]

15. Jin, J.E.; Jung, Y.S.; Lee, Y.K. Effect of grain size on the uniform ductility of a bulk ultrafine-grained alloy. Mater. Sci. Eng. A 2007, 449, 786-789. [CrossRef]

16. Matsuoka, Y.; Iwasaki, T.; Nakada, N.; Tsuchiyama, T.; Takaki, S. Effect of grain size on thermal and mechanical stability of austenite in metastable austenitic stainless steel. ISIJ Int. 2013, 53, 1224-1230. [CrossRef]

17. Kisko, A.; Misra, R.D.K.; Talonen, J.; Karjalainen, L.P. The influence of grain size on the strain-induced martensite formation in tensile straining of an austenitic $15 \mathrm{Cr}-9 \mathrm{Mn}-\mathrm{Ni}-\mathrm{Cu}$ stainless steel. Mater. Sci. Eng. A 2013, 578, 408-416. [CrossRef]

18. De, A.K.; Murdock, D.C.; Mataya, M.C.; Speer, J.G.; Matlock, D.K. Quantitative measurement of deformation-induced martensite in 304 stainless steel by X-ray diffraction. Scr. Mater. 2004, 50, 1445-1449. [CrossRef]

19. Chen, L.; Yuan, F.; Jiang, P.; Wu, X. Mechanical properties and nanostructures in a duplex stainless steel subjected to equal channel angular pressing. Mater. Sci. Eng. A 2012, 551, 154-159. [CrossRef]

20. Dakhlaoui, R.; Braham, C.; Baczmański, A. Mechanical properties of phases in austeno-ferritic duplex stainless steel-Surface stresses studied by X-ray diffraction. Mater. Sci. Eng. A 2007, 444, 6-17. [CrossRef]

21. Sinclair, C.W.; Saada, G.; Embury, J.D. Role of internal stresses in co-deformed two-phase materials. Philos. Mag. 2006, 86, 4081-4098. [CrossRef]

22. Wu, X.; Zhu, Y. Heterogeneous materials: a new class of materials with unprecedented mechanical properties. Mater. Res. Lett. 2017, 5, 527-532. [CrossRef]

23. Li, Y.; Li, W.; Hu, J.C.; Song, H.M.; Jin, X.J. Compatible strain evolution in two phases due to epsilon martensite transformation in duplex TRIP-assisted stainless steels with high hydrogen embrittlement resistance. J. Int. Plast. 2017, 88, 53-69. [CrossRef] 
24. Sowerby, R.; Uko, D.K.; Tomita, Y. A review of certain aspects of the Bauschinger effect in metals. Mater. Sci. Eng. 1979, 41, 43-58. [CrossRef]

25. Yang, M.; Pan, Y.; Yuan, F.; Zhu, Y.; Wu, X. Back stress strengthening and strain hardening in gradient structure. Mater. Res. Lett. 2016, 4, 145-151. [CrossRef]

26. Yang, M.X.; Yuan, F.P.; Xie, Q.G.; Wang, Y.D.; Ma, E.; Wu, X.L. Strain hardening in Fe-16Mn-10Al-0.86 C-5Ni high specific strength steel. Acta Mater. 2016, 109, 213-222. [CrossRef]

27. Jia, N.; Peng, R.L.; Wang, Y.D.; Chai, G.C.; Johansson, S.; Wang, G.; Liaw, P.K. Interactions between the phase stress and the grain-orientation-dependent stress in duplex stainless steel during deformation. Acta Mater. 2006, 54, 3907-3916. [CrossRef]

28. Fang, X.; Yin, W.; Qin, C.; Wang, W.; Lo, K.H.; Shek, C.H. The interface character distribution of cold-rolled and annealed duplex stainless steel. Mater. Charact. 2016, 118, 397-404. [CrossRef]

29. Ashby, M.F. The deformation of plastically non-homogeneous materials. Philos. Mag. A 1970, $21,399-424$. [CrossRef]

30. Mughrabi, H. On the role of strain gradients and long-range internal stresses in the composite model of crystal plasticity. Mater. Sci. Eng. A 2001, 317, 171-180. [CrossRef]

31. Ma, E. Instabilities and ductility of nanocrystalline and ultrafine-grained metals. Scr. Mater. 2003, 49, 663-668. [CrossRef]

32. Koch, C.C. Ductility in nanostructured and ultrafine-grained materials: Recent evidence for optimism. J. Metastab. Nanocrystalline Mater. 2003, 18, 9-20. [CrossRef]

33. Tsuji, N.; Ito, Y.; Saito, Y.; Minamino, Y. Strength and ductility of ultrafine grained aluminum and iron produced by ARB and annealing. Scr. Mater. 2002, 47, 893-899. [CrossRef]

34. Kamikawa, N.; Huang, X.; Tsuji, N.; Hansen, N. Strengthening mechanisms in nanostructured high-purity aluminium deformed to high strain and annealed. Acta Mater. 2009, 57, 4198-4208. [CrossRef]

35. Huang, T.; Dong, Q.; Gong, X.; Hansen, N.; Liu, Q.; Huang, X. Cold rolled nanostructured super-pure Al (99.9996\%) containing 1\% Si particles: Structure and strength. J. Mater. Sci. 2012, 47, 7914-7920. [CrossRef]

36. Li, Z.; Fu, L.; Fu, B.; Shan, A. Yield point elongation in fine-grained titanium. Mater. Lett. 2013, 96, 1-4. [CrossRef]

37. Gao, S.; Chen, M.; Joshi, M.; Shibata, A.; Tsuji, N. Yielding behavior and its effect on uniform elongation in IF steel with various grain sizes. J. Mater. Sci. 2014, 49, 6536-6542. [CrossRef]

38. Calcagnotto, M.; Ponge, D.; Raabe, D. Effect of grain refinement to $1 \mu \mathrm{m}$ on strength and toughness of dual-phase steels. Mater. Sci. Eng. A 2010, 527, 7832-7840. [CrossRef]

39. Calcagnotto, M.; Adachi, Y.; Ponge, D.; Raabe, D. Deformation and fracture mechanisms in fine-and ultrafine-grained ferrite/martensite dual-phase steels and the effect of aging. Acta Mater. 2011, 59, 658-670. [CrossRef]

40. Tomota, Y.; Kuroki, K.; Mori, T.; Tamura, I. Tensile deformation of two-ductile-phase alloys: Flow curves of $\alpha-\gamma$ Fe-Cr-Ni alloys. Mater. Sci. Eng. 1976, 24, 85-94. [CrossRef]

41. Sohn, S.S.; Choi, K.; Kwak, J.H.; Kim, N.J.; Lee, S. Novel ferrite-austenite duplex lightweight steel with 77\% ductility by transformation induced plasticity and twinning induced plasticity mechanisms. Acta Mater. 2014, 78, 181-189. [CrossRef]

42. Berrahmoune, M.R.; Berveiller, S.; Inal, K.; Moulin, A.; Patoor, E. Analysis of the martensitic transformation at various scales in TRIP steel. Mater. Sci. Eng. A 2004, 378, 304-307. [CrossRef]

43. Van Dijk, N.H.; Butt, A.M.; Zhao, L.; Sietsma, J.; Offerman, S.E.; Wright, J.P.; Van der Zwaag, S. Thermal stability of retained austenite in TRIP steels studied by synchrotron X-ray diffraction during cooling. Acta Mater. 2005, 53, 5439-5447. [CrossRef]

44. Saha, R.; Ueji, R.; Tsuji, N. Fully recrystallized nanostructure fabricated without severe plastic deformation in high-Mn austenitic steel. Scr. Mater. 2013, 68, 813-816. [CrossRef]

45. Hahn, G.T. A model for yielding with special reference to the yield-point phenomena of iron and related bcc metals. Acta Metall. 1962, 10, 727-738. [CrossRef]

46. Yu, C.Y.; Kao, P.W.; Chang, C.P. Transition of tensile deformation behaviors in ultrafine-grained aluminum. Acta Mater. 2005, 53, 4019-4028. [CrossRef]

47. Sugimoto, K.I.; Usui, N.; Kobayashi, M.; Hashimoto, S.I. Effects of volume fraction and stability of retained austenite on ductility of TRIP-aided dual-phase steels. ISIJ Int. 1992, 32, 1311-1318. [CrossRef] 
48. Sugimoto, K.I.; Iida, T.; Sakaguchi, J.; Kashima, T. Retained austenite characteristics and tensile properties in a TRIP type bainitic sheet steel. ISIJ Int. 2000, 40, 902-908. [CrossRef]

49. Jacques, P.J.; Delannay, F.; Ladrière, J. On the influence of interactions between phases on the mechanical stability of retained austenite in transformation-induced plasticity multiphase steels. Metall. Mater. Trans. A 2001, 32, 2759-2768. [CrossRef]

50. Wang, Y.; Kang, J.; Peng, Y.; Wang, T.; Hansen, N.; Huang, X. Laminated Fe-34.5Mn-0.04C composite with high strength and ductility. J. Mater. Sci. Technol. 2018, 34, 1939-1943. [CrossRef]

(C) 2019 by the authors. Licensee MDPI, Basel, Switzerland. This article is an open access article distributed under the terms and conditions of the Creative Commons Attribution (CC BY) license (http://creativecommons.org/licenses/by/4.0/). 